\title{
Ectopic thyroid papillary carcinoma of nasopharynx associated with adenoid hypertrophy: an unusual presentation
}

\author{
Linli Tian', Yufei Jiao², Ming Liu', Minghua Li ${ }^{1}$ and Hongchao Yao ${ }^{1,3^{*}}$
}

\begin{abstract}
Ectopic thyroid tissue of nasopharynx is an uncommon phenomenon and papillary thyroid carcinoma arising from the tissue is extremely rare. The authors report a rare case of 16-year-old girl with papillary thyroid carcinoma of nasopharynx. Clinicians were ever confused by adenoid hypertrophy and solved the diagnostic dilemma by adequate examinations. In the case, we mainly emphasize that surgeons should be aware of and actively consider such a possibility of ectopic papillary thyroid carcinoma of nasopharynx in children and adolescents with long-term nasal obstruction, even if thyroid carcinoma is a rare tumor.
\end{abstract}

Keywords: Ectopic thyroid papillary carcinoma, Nasopharynx, Adenoid hypertrophy, Nasal obstruction

\section{Introduction}

Ectopic thyroid tissue is rare, which the reported incidence is 1 in every 100,000 to 300,000 in the general population [1,2]. A thyroid gland can reside anywhere along thyroid embryologic path from the foramen cecum to its normal site such as lingua, thyroglossal duct and laryngotrachea [3]. The abnormal migration of the thyroid is known as ectopic thyroid [4]. Ectopic thyroid tissue, especially ectopic papillary thyroid carcinoma (PTC) of nasopharynx, is extremely rare, and may cause diagnostic and therapic dilemma for clinicians just as our case. To our knowledge, very few reports of ectopic nasopharyngeal thyroid cancer with a normal eutopic thyroid gland have been published to date [5,6]. Herein we present an uncommon case of ectopic PTC of nasopharynx associated with adenoidal hypertrophy and share our experience of the successful management about such a rare case.

\section{Case report}

A 16-year-old girl presented to the Department of ENT and Head and Neck Surgery at the Second Affiliated

\footnotetext{
* Correspondence: 176631236@qq.com

'Department of Otolaryngology, Head and Neck Surgery, The Second

Affiliated Hospital, Harbin Medical University, Harbin, China

${ }^{3}$ Department of Otorhinolaryngology, Head and Neck Surgery, Second

Affiliated Hospital, Harbin Medical University, Harbin 150081, China

Full list of author information is available at the end of the article
}

Hospital of Harbin Medical University with a history of persistent nasal obstruction of 7 years duration. The girl was diagnosed with adenoid hypertrophy 5 years ago by simple CT scan examination (unavailable). At that time, the patient's family refused any further examinations and treatment for fear of surgery. By this time, clinical examination revealed no pyrexia, heart rate $90 \mathrm{bpm}$ and normal life signs. Physical examination revealed a nasopharyngeal mass blocking the majority of postnaris. Nasal endoscopic examination found oval mass with pedicle located in the nasopharyngeal posterior wall across hypertrophic adenoid. The tumor was smooth, enveloped with a clear demarcation. A CT scan showed a solid cystic mass located in the nasopharynx (Figure 1). The thyroid gland was normal and no cervical lymphadenopathy was noted. Following biopsy pathology, papillary thyroid carcinoma was diagnosed (Figures 2 and 3). Tumor resection was performed through FESS under general anesthesia 3 days later. Postoperative pathological examination further confirmed papillary thyroid carcinoma in the nasopharyngeal mass with histopathological features of pleomorphic malignant oval to rounded epithelial cells (Figure 2A) and ground glass nuclei and nuclear grooves of cells (Figure 3). Immunohistochemical analysis revealed positive cytokeratin (CK), thyroglobulin (TG) and thyroid transcription factor-1 (TTF-1) as diagnostic PTC markers (Figure 2B,C,D). The postoperative period was uneventful 


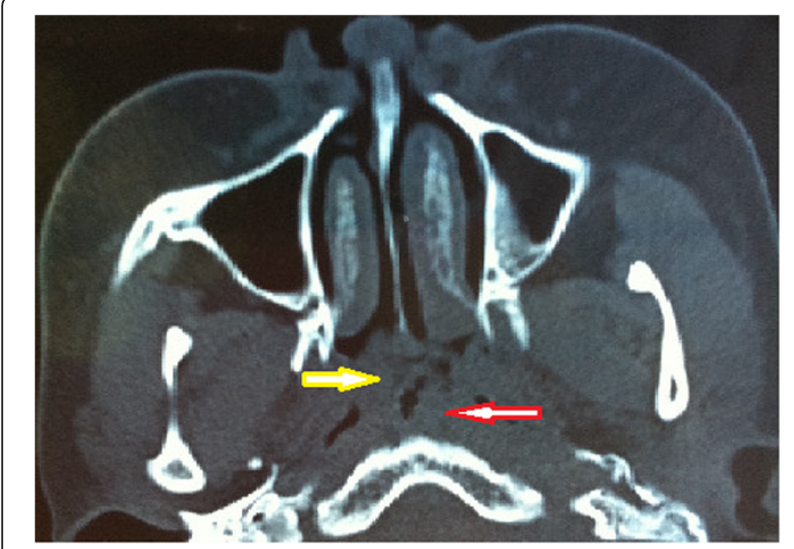

Figure 1 Preoperative CT findings of the patient. Overlapping image of ectopic PTC (yellow arrow) and hypertrophic adenoid (red arrow) in nasopharynx.

and the patient was discharged from the hospital 5 days later. The patient could not be treated with thyroidectomy and radioactive iodine therapy because relatives of patient refused the recommendation. Upon follow-up at 6 months, the patient remains asymptomatic.

\section{Discussion}

Thyroid carcinoma is a relatively rare pediatric pathology, comprising around 3\% of children and adolescents tumors [7]. Papillary thyroid carcinoma, a kind of differentiated thyroid cancer, is the most common neoplasm

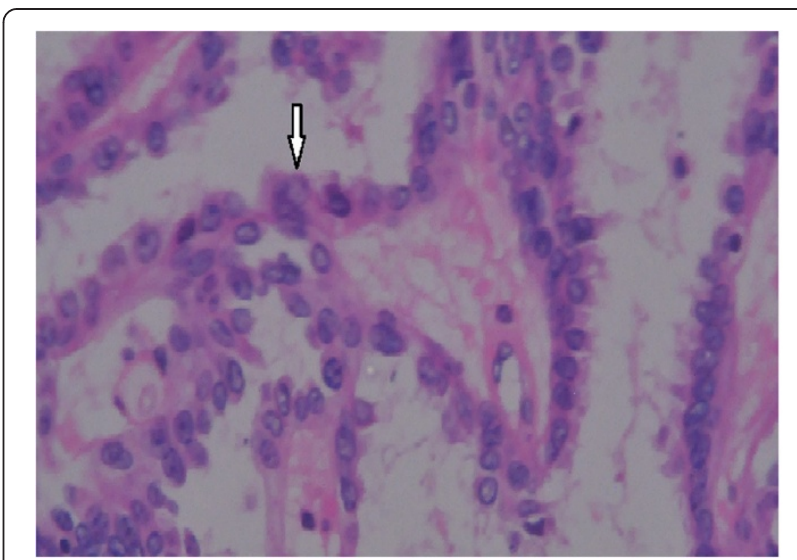

Figure $3 \mathrm{H}$ \& E stain showed nuclear features such as ground glass nuclei and nuclear grooves (arrow). Magnification: $\times 400$.

in the thyroid gland and accounts for about $80 \%$ of all thyroid cancers [8]. Ectopic papillary thyroid carcinoma has been found in some places such as lingua [3], mediastinum [9] and thyroglossal duct [10]. Ectopic PTC of nasopharynx is extremely scarce especially with normal eutopic thyroid gland and no lymph node involvement just as our case.

The girl of our case had long-term nasal obstruction and was diagnosed as adenoid hypertrophy before 5 years by means of simple CT scan examination. Because of increasing nasal obstruction, the patient was checked by further examinations including CT scan and endoscopy
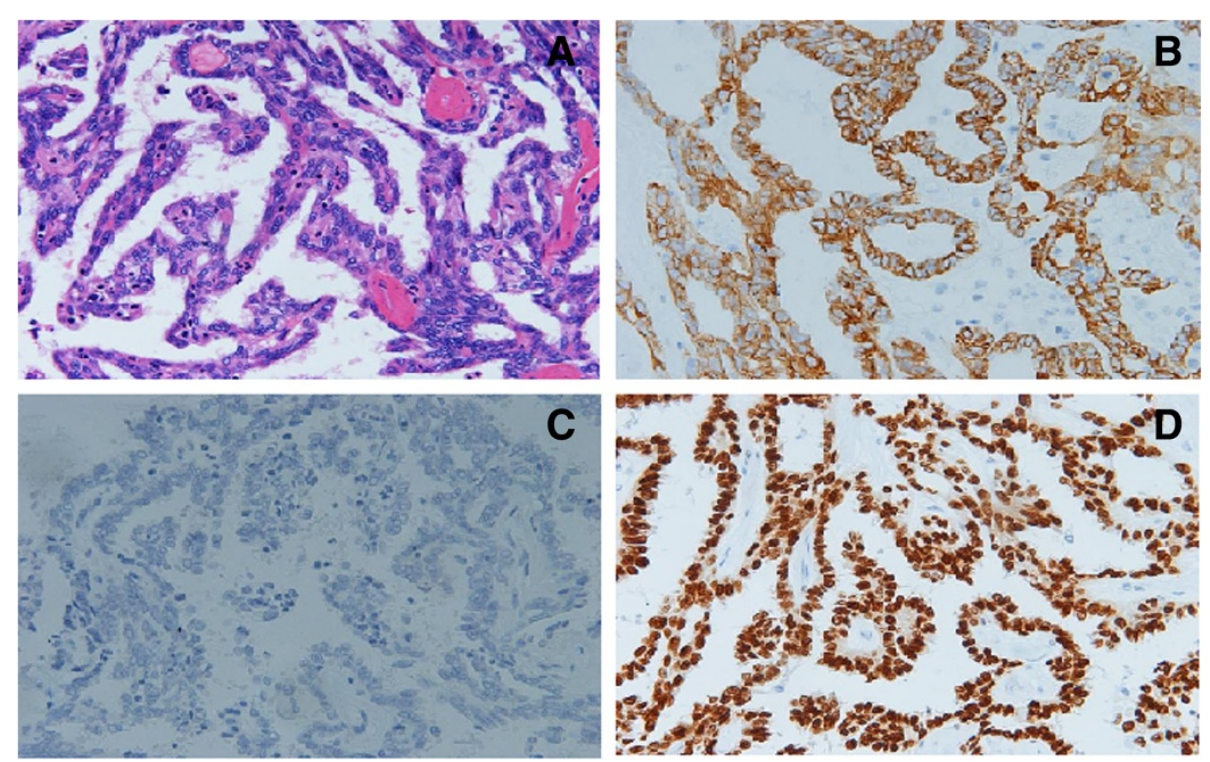

Figure 2 Histopathological examination of thyroid showing papillary carcinoma. A: H \& E stain showed moderately pleomorphic malignant oval to rounded epithelial cells. B, C, D: Immunohistochemical analysis revealed positive CK (B), TG (C) and TTF-1 (D) as markers of PTC. Magnification: $\times 200$. 
and an oval neoplasm with intact capsule was found to be located on nasopharynx near hypertrophic adenoid. This case suggested that nasal obstruction of children and adolescent could be caused by not only lymphoid tissue hyperplasia and common neoplasms but also unusual tumors. Then, biopsy showed histological characteristics of papillarity, ground glass nuclei and nuclear grooves of cells, suggesting this was a thyroid-like tumor of malignant origin. Additional examination of immunohistochemistry revealed that the positive expressions of TTF-1, CK and TG and negative for P63. TTF-1 is currently used in routine surgical pathology as an immunohischemical marker of primary carcinomas arising in thyroid and lung organs. It has also been reported to be expressed in other tumors such as thymoma, ovarian, endocervical and endometrial neoplasms [11,12]. According to the histological characteristics and immunohistochemical features, we made a final diagnosis of papillary thyroid carcinoma on nasopharynx. Other thyroid-like tumors such as low-grade papillary adenocarcinoma of the nasopharynx (LGPACNP) also exhibit similar features $[13,14]$. However, the fact that the positive expression of TG has hitherto not been mentioned in previous reports of LGPACNP could exclude this diagnostic possibility [15]. In addition, normal thyroid gland in its pretracheal position and no cervical lymphadenopathy gave us evidence to support our diagnosis of ectopic PTC rather than metastasis of thyroid carcinoma [16].

Treatment outcomes of PTC are very favorable and have an excellent prognosis with 10-year survival rates of more than $90 \%[17,18]$. The optional treatment methods have surgery, radiotherapy, radioactive iodine therapy, and chemotherapy according to the current management guidelines for patients with differentiated thyroid cancer issued by the American Thyroid Association [19]. Adequate surgical treatment followed by postoperative radioactive iodine therapy can offer very promising results for ectopic PTC.

\section{Conclusion}

In conclusion, even if thyroid carcinoma is a rare tumor in children and adolescents, surgeons should be aware of and actively consider such a possibility of ectopic papillary thyroid carcinoma of nasopharynx in patients with nasal obstruction. Since the clinical signs and symptoms are most often vague mimicking other nasopharyngeal diseases, ectopic thyroid carcinoma should be considered in the differential diagnosis even in the presence of a normal thyroid gland. Imageological examinations such as CT scan and biopsy are usually necessary for diagnosis and treatment. The present case report shows that there is always a chance to encounter exceedingly rare disease and adequate examinations of pre-operation are necessary for appropriate diagnosis and treatment.

\section{Consent}

Written informed consent was obtained from the patient's next of kin for publication of this case report and any accompanying images. A copy of the written consent is available for review by the Editor-in-Chief of this journal. The review board of Harbin Medical University approved publication of this case report.

\section{Competing interests}

The authors declare that they have no competing interests.

\section{Authors' contributions}

LT and ML, surgery and manuscript editing; YJ, pathological diagnosis and manuscript editing; $\mathrm{ML}$, clinical consultation and manuscript editing; $\mathrm{HY}$ surgery and manuscript revision. All authors read and approved the final manuscript.

\section{Author details}

'Department of Otolaryngology, Head and Neck Surgery, The Second Affiliated Hospital, Harbin Medical University, Harbin, China. ${ }^{2}$ Department of Pathology, The Second Affiliated Hospital, Harbin Medical University, Harbin, China. ${ }^{3}$ Department of Otorhinolaryngology, Head and Neck Surgery, Second Affiliated Hospital, Harbin Medical University, Harbin 150081, China.

Received: 25 June 2014 Accepted: 18 September 2014 Published: 20 September 2014

\section{References}

1. Sevinç Al, Unek T, Canda AE, Guray M, Kocdor MA, Saydam S, Harmancioglu O: Papillary carcinoma arising in subhyoid ectopic thyroid gland with no orthotopic thyroid tissue. Am J Surg 2010, 200(1):e17-e18.

2. Noussios G, Anagnostis P, Goulis DG, Lappas D, Natsis K: Ectopic thyroid tissue: anatomical, clinical, and surgical implications of a rare entity. Eur J Endocrinol 2011, 165(3):375-382.

3. Massine RE, Durning SJ, Koroscil TM: Lingual thyroid carcinoma: a case report and review of the literature. Thyroid 2001, 11(12):1191-1196.

4. Hazarika P, Murty PS, Nooruddin SM, Zachariah J, Rao NR: Lingual thyroid. Ear Nose Throat J 1988, 67(3):161-165.

5. Tong A, Xia W, Qi F, Jin Z, Yang D, Zhang Z, Li F, Xing X, Lian X: Hyperthyroidism caused by an ectopic thyrotropin-secreting tumor of the nasopharynx: a case report and review of the literature. Thyroid 2013, 23(9):1172-1177.

6. Karras S, Anagnostis P, Noussios G, Pontikides N: Thyroid papillary carcinoma arising in ectopic thyroid tissue within a branchial cleft cyst. BMJ Case Rep 2013, 22:2013.

7. Dzepina D: Surgical and pathological characteristics of papillary thyroid cancer in children and adolescents. Int J Pediatr 2012, 2012:125389.

8. Hodak SP, Burman KD: The calcitonin conundrum-is it time for routine measurement of serum calcitonin in patients with thyroid nodules? J Clin Endocrinol Metab 2004, 89(2):511-514.

9. Choi JY, Kim JH: A case of an ectopic thyroid gland at the lateral neck masquerading as a metastatic papillary thyroid carcinoma. J Korean Med Sci 2008, 23(3):548-550.

10. Lianos G, Bali C, Tatsis V, Anastasiadi Z, Lianou E, Papathanasiou V, Messinis T: Ectopic thyroid carcinoma. Case report. G Chir 2013, 34(4):114-116.

11. Kubba LA, McCluggage WG, Liu J, Malpica A, Euscher ED, Silva EG, Deavers MT: Thyroid transcription factor-1 expression in ovarian epithelial neoplasms. Mod Pathol 2008, 21:485-490.

12. Siami K, McCluggage WG, Ordonez NG, Euscher ED, Malpica A, Sneige N Silva EG, Deavers MT: Thyroid transcription factor-1 expression in endometrial and endocervical adenocarcinomas. Am J Surg Pathol 2007, 31:1759-1763.

13. Wenig BM, Hyams VJ, Heffner DK: Nasopharyngeal papillary adenocarcinoma. A clinicopathologic study of a low-grade carcinoma. Am J Surg Pathol 1988, 12:946-953.

14. Petersson F, Pang B, Loke D, Hao L, Yan B: Biphasic low-grade nasopharyngeal papillary adenocarcinoma with a prominent spindle cell component: report of a case localized to the posterior nasal septum. Head Neck Pathol 2011, 5(3):306-313 
15. Glicksman JT, Franklin JH, Shepherd J, Rotenberg BW: An endonasal approach to the resection of a papillary seromucinous adenocarcinoma of the Eustacian tube. J Otolaryngol Head Neck Surg 2013, 42(1):12.

16. Haq M, Harmer C: Thyroid cancer: an overview [J]. Nucl Med Commun 2004, 25(9):861-867.

17. Volante M, Collini P, Nikiforov YE, Sakamoto A, Kakudo K, Katoh R, Lloyd RV, LiVolsi VA, Papotti M, Sobrinho-Simoes M, Bussolati G, Rosai J: Poorly differentiated thyroid carcinoma: the turin proposal for the use of uniform diagnostic criteria and an algorithmic diagnostic approach. Am J Surg Pathol 2007, 31(8):1256-1264.

18. Verburg FA, Mader U, Luster M, Reiners C: Primary tumour diameter as a risk factor for advanced disease features of differentiated thyroid carcinoma. Clin Endocrinol (Oxf) 2009, 71(2):291-297.

19. American Thyroid Association (ATA) Guidelines Taskforce on Thyroid Nodules and Differentiated Thyroid Cancer, Cooper DS, Doherty GM Haugen BR, Kloos RT, Lee SL, Mandel SJ, Mazzaferri EL, Mclver B, Pacini F, Schlumberger M, Sherman SI, Steward DL, Tuttle RM: Revised American Thyroid Association management guidelines for patients with thyroid nodules and differentiated thyroid cancer. Thyroid 2009, 19(11):1167-1214.

doi:10.1186/1746-160X-10-40

Cite this article as: Tian et al.: Ectopic thyroid papillary carcinoma of nasopharynx associated with adenoid hypertrophy: an unusual presentation. Head \& Face Medicine 2014 10:40

\section{Submit your next manuscript to BioMed Central and take full advantage of:}

- Convenient online submission

- Thorough peer review

- No space constraints or color figure charges

- Immediate publication on acceptance

- Inclusion in PubMed, CAS, Scopus and Google Scholar

- Research which is freely available for redistribution 